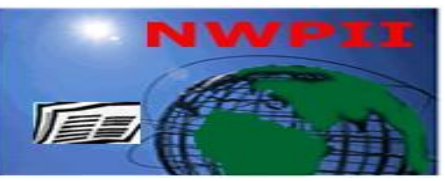

American Journal of Biomedical Sciences

ISSN: 1937-9080

nwpii.com/ajbms

\title{
Serum Proteomic Profiling of Lung Adenocarcinoma with Brain Metastasis Based on Matrix-Assisted Laser Ionization Time of Flight Mass Spectrometry Analysis
}

\author{
Wenjun Mou ${ }^{1,2}$, Hongli Tong ${ }^{1}$,Chao Ren ${ }^{3}$,Chunyan Zhang ${ }^{1,2}$, Yanhong Gao ${ }^{1}$, \\ Xinyu Wen ${ }^{1}$ and Yaping Tian ${ }^{1}$
}

\author{
${ }^{1}$ Department of Clinical Biochemistry, Chinese PLA General Hospital, Beijing 100853, China. \\ ${ }^{2}$ School of Medicine, Nankai University, Tianjin 300071, China, \\ ${ }^{3}$ Department of Radiology, Chinese PLA General Hospital, Beijing 100853, China \\ *Corresponding author: \\ Yaping Tian \\ Department of Clinical Biochemistry \\ Chinese PLA General Hospital \\ 28th Fuxing Rd, Beijing 100853 \\ PR China \\ Tel:+86-10-6693-9374 \\ Fax:+86-10-8821-7385 \\ E-mail: tianyp61@gmail.com.
}

Received: 31 March 2014; | Revised: 13 May 2014; | Accepted: 11 June 2014

\begin{abstract}
Background: Once patients presented with brain metastasis, the prognosis is poor with shortened survival of up to 6 months, and therefore early recognition of brain metastasis may be beneficial to outcomes of patients. The present work focused on serum proteomic biomarkers that represent the status of lung adenocarcinoma especially for patients with brain metastasis. Methods: 100 serum samples including 25 from lung adenocarcinoma patients with brain metastasis , 25 from lung adenocarcinoma patients without metastasis and 50 from healthy controls were analyzed using matrix-assisted laser desorption/ionization time-of-flight mass spectrometry (MALDI-TOF-MS). ClinProt software and binary logistic regression method were used to develop classification model using MS spectral data. Univariate and Cox multivariate analysis were also performed to evaluate the potential prognostic value of serum peptides. Results: A series of 14 significant short peptides was detected in serum of lung adenocarcinoma patients as compared with healthy controls. Of these, a panel consisting of peptides $\mathrm{m} / \mathrm{z} 1969.9$ and $2213.4 \mathrm{Da}$ had the highest diagnostic value for discriminating lung adenocarcinoma from healthy controls with a sensitivity of $91.7 \%$ and a specificity of $79.2 \%$. The panel consisting of peptides $\mathrm{m} / \mathrm{z} 1781.5$ and $1984.7 \mathrm{Da}$ had the highest diagnostic value for discriminating advanced lung adenocarcinoma with brain metastasis from patients without metastasis with a sensitivity of $84.6 \%$ and a specificity of $79.2 \%$. Univariate and Cox multivariate analysis disclosed that peptide $\mathrm{m} / \mathrm{z}$ 1969.9 Da remained an independent predictors for lung adenocarcinoma patients while peptide $\mathrm{m} / \mathrm{z}$ 1984.7 Da shows favourable value on pre-warning lung adenocarcinoma patients
\end{abstract}


with brain metastasis after chemotherapy. Conclusion: We have completed a preliminary study to describe the serum proteomic profile of lung adenocarcinoma patients with brain metastasis, and our proteomic models may improve the diagnosis and prognosis of lung adenocarcinoma patients and helps us to better understand the pathogenesis of disease process of brain metastasis.

Keywords: Classification model, prognostic value, serum peptides, lung adenocarcinoma, brain metastasis.

\section{Introduction}

Metastatic spread to brain are common for patients with Non-small cell lung cancer (NSCLC) (8). At initial diagnosis, 20\% of NSCLC patients have brain metastasis (BM), approximately $40-50 \%$ develop BM during the course of treatment $(16,19,24)$. For NSCLC patients with $\mathrm{BM}$, the primary treatment remains systemic chemotherapy, surgery and radiotherapy, and therefore one might expect this to be a logical choice for patients with $\mathrm{BM}$ as well. Some patients with $\mathrm{BM}$ respond to the treatment to some degree $(1,12)$. But, several issues have limited the application of chemotherapy, among which BM is a major barrier of restricting the use of chemotherapy at some point during the disease $(6,22)$. Early recognition of $\mathrm{BM}$ may be beneficial to outcomes. Although several screening techniques, such as analysis of serum tumor markers (23) are recommended, the sensitivity and specificity is relatively low. So it is necessary to explore effective biomarkers for pre-warning the condition of patients.

The usefulness of proteomic analysis for monitoring the condition of cancer patients is now widely recognized $(2,5,7,20)$. In recent years, it has been demonstrated that the serum contains thousands of peptides, most of which are thought to be degraded fragments of large proteins due to the interaction between tumor cells and tumor microenvironment $(18,26)$. And some of these peptides may function as biomarkers for specific physiological and pathological process, with their changes in quantity and quality being correlated with pathological status and thus useful for monitoring the condition of patients. The matrix-assisted laser desorption/ionization time-of-flight mass spectrometry (MALDI-TOF MS) has already been used to detect peptides of low molecular weights at high sensitivity and resolution among cancer patients, which make it a convenient platform for serum peptides profiling $(3,4,21)$.

In the present study, we analyzed serum proteomic pattern in lung adenocarcinoma patients using MALDI-TOF MS. We aim to find potential peptides that represent the status of lung adenocarcinoma especially for patients with BM and establishing classification models for lung adenocarcinoma patients.

\section{Materials and methods}

\subsection{Patients and Sample Collection}

Fifty healthy controls and 50 histologically confirmed lung adenocarcinoma patients were enrolled between July 1st, 2012 and June 30th, 2013. The study was performed with the permission of the Ethical Commission of PLA general hospital. Informed consent was also obtained from each patient. In terms of the chemotherapy regimen, all patients received $4 \sim 6$ cycles of $500 \mathrm{mg} / \mathrm{m}^{2}$ pemetrexed combined with $75 \mathrm{mg} / \mathrm{m}^{2}$ cisplatin every 21 days. Brain magnetic resonance imaging (MRI) was performed in all lung adenocarcinoma patients to confirm the presence of BM every two cycles. Serum samples without freeze thawing were stored in small aliquots at $-80^{\circ} \mathrm{C}$ until used.

\subsection{Mass Spectrometry Analysis}

Peptides are purified using magnetic bead based weak cation exchange (MB-WCX) on ClinProt platform( Bruker Daltonics Inc., Fremont, CA) (14) according to the manufacturer's instructions. For proteome analysis, we used an Autoflex III MALDI-TOFMS with the following setting: ion source 1,120 $\mathrm{kV}$; ion source $2,186 \mathrm{kV}$; lens, $7.6 \mathrm{kV}$. For each sample, 1600 spectra were acquired (400 laser shots at 8 different spot positions) using linear 
positive mode. Spectra were collected automatically using the autoflex Analysis software (Bruker Daltonik) to generate raw data of optimized quality.

\subsection{Statistical analysis}

All statistical analyses were performed using the SPSS version 20.0 statistical software (SPSS, Inc., Chicago, IL). The ClinProt software 2.0 (Bruker Daltonics Inc., Fremont, CA was used for analysis of all serum sample data derived from either lung adenocarcinoma patients or healthy controls. Statistically significant different quantity of peptides was determined by means of t-tests or Mann-Whitney U-test. The classification models were generated by binary logistic regression. And the progression-free survival (PFS) time was calculated from the day of diagnosis to the day of progression or day of the last follow-up. The cut-off, spearman correlation analysis and AUC (area under the curve) values of selected peptides were carried out using SPSS statistical software as well. The PFS curves were determined using the KaplanMeier method and compared between groups using the log-rank test. The independent prognostic factors were conducted by univariate analysis and Cox multivariate analysis. Significance was defined by a $\mathrm{p}$-value $<0.05$.

\section{Results}

\subsection{Patient characteristics and lung adenocarcinoma-related peptides}

The characteristics of the 50 lung adenocarcinoma patients and 50 healthy controls are shown in Table 1, Table 2. The lung adenocarcinoma patients included 31 males and 29 females whose median age was 51 years (range: $27-78$ years). Almost two-fifth were current smokers while non-smokes and exsmokers account for $36 \%$ and $26 \%$ respectively. A total of 16 patients (32\%) were low differentiated, 12 patients $(24 \%)$ were moderate or well differentiated and the remaining 17 patients (34\%) with an unknown status. 25 patients were presented I IIIA without BM while the other 25 patients presenting in stage IIIB IV with BM.

All the 100 serum samples were detected by MADLI-TOF-MS (mass 1,000 10,000 Da) in combination with MB-WCX magnetic bead. We evaluated proteomic changes in the serum samples of 50 lung adenocarcinoma patients as compared with 50 heathy controls. As shown in table 3 , a set of 14 peptide peaks which showed significant differences between lung adenocarcinoma patients and healthy controls were selected by ClinPro software.

Table 1. Baseline characteristics of the 50 lung adenocarcinoma patients.

\begin{tabular}{lc}
\hline Clinical Parameters & \% of Patients \\
\hline Age,years & \\
Median & 51 \\
Range & $27 \sim 78$ \\
Gender,n(\%) & \\
Male & $31(62 \%)$ \\
Female & $19(38 \%)$ \\
Smoking status & \\
Non-smokers & $18(36 \%)$ \\
Ex-smokers & $13(26 \%)$ \\
Smokers & $19(38 \%)$ \\
Tumor differentiation & \\
Low & $16(32 \%)$ \\
Moderate or well & $12(24 \%)$ \\
unkown & $17(34 \%)$ \\
Stage,n(\%) & \\
I IIIA & $25(50 \%)$ \\
IIIB IV & $25(50 \%)$ \\
Brain Metastasis & \\
Yes & $25(50 \%)$ \\
No & $25(50 \%)$ \\
Histology,n(\%) & \\
Adenocarcinoma & $50(100 \%)$ \\
\hline
\end{tabular}


Table 2. Basic information of the studied subjects

\begin{tabular}{lccc}
\hline \multicolumn{1}{c}{ Histology } & $\begin{array}{c}\text { No. of } \\
\text { patients }\end{array}$ & $\begin{array}{c}\text { Age, mean, median } \\
\text { (range) }\end{array}$ & $\begin{array}{c}\text { Sex (female, } \\
\text { male) }\end{array}$ \\
\hline Healthy control & 50 & $49.81,50(22,74)$ & 27,23 \\
Lung adenocarcinoma without BM & 25 & $52.56,53(27,78)$ & 9,16 \\
Lung adenocarcinoma with BM & 25 & $51.13,50(29,73)$ & 10,15 \\
\hline
\end{tabular}

Table 3. Peptide peaks differentially expressed between lung adenocarcinoma patients and healthy controls

\begin{tabular}{ccccc}
\hline Peptides & Normal & Adenocarcinoma & trend & $\mathbf{p}$ \\
\hline 1781.8 & 176.4 & 469.1 & $\uparrow$ & 0.000289 \\
1869.1 & 331.5 & 814.4 & $\uparrow$ & 0.000448 \\
1947.9 & 1946 & 2270.3 & $\uparrow$ & 0.004 \\
1969.9 & 264.6 & 432 & $\uparrow$ & 0.00012 \\
2663.8 & 342.5 & 856.3 & $\uparrow$ & 0.008 \\
2865.8 & 227.3 & 449 & $\uparrow$ & $<1 \mathrm{e}-6$ \\
3244.4 & 590.7 & 1390.8 & $\uparrow$ & 0.0000116 \\
4096.2 & 109.8 & 272.8 & $\uparrow$ & 0.006 \\
4214.1 & 514.1 & 1203.2 & $\uparrow$ & 0.000582 \\
5910.2 & 454.8 & 886.2 & $\uparrow$ & 0.016 \\
1984.7 & 239.2 & 149.1 & $\downarrow$ & 0.008 \\
2095.2 & 1931.3 & 992.7 & $\downarrow$ & 0.00000854 \\
2107.1 & 586 & 218.6 & $\downarrow$ & 0.000102 \\
2213.4 & 4036.9 & 2088.9 & $\downarrow$ & 0.0000739 \\
\hline
\end{tabular}

Table 5. Univariate logistic regression analysis of the 4 pre-selected peptides

\begin{tabular}{lcccccc}
\hline \multicolumn{1}{c}{ Peptides } & B & S.E. & Wald & df & Sig. & $\operatorname{Exp(B)}$ \\
\hline 1969.9 & -0.009 & 0.005 & 3.09 & 1 & 0.079 & 0.991 \\
2107.1 & 0.003 & 0.004 & 0.65 & 1 & 0.42 & 1.003 \\
2213.4 & -0.002 & 0.001 & 8.761 & 1 & 0.003 & 0.998 \\
1947.9 & 0 & 0.001 & 0 & 1 & 0.999 & 1 \\
Constant & 6.993 & 2.367 & 8.73 & 1 & 0.003 & 1089 \\
\hline
\end{tabular}

Table 6. Peptides used in the multivariate logistic regression analysis for developing the classification model (lung adenocarcinoma vs. healthy controls)

\begin{tabular}{lcccccccc}
\hline Peptides & \multirow{2}{*}{ B } & S.E. & Wald & df & Sig. & \multirow{2}{*}{$\operatorname{Exp}(\mathbf{B})$} & \multicolumn{2}{c}{$\mathbf{9 5 . 0 \%}$ C.I. for $\operatorname{EXP}(\mathbf{B})$} \\
\hline 1969.9 & -0.006 & 0.002 & 6.353 & 1 & 0.012 & 0.994 & 0.989 & 0.999 \\
2213.4 & -0.002 & 0.001 & 10.198 & 1 & 0.001 & 0.998 & 0.997 & 0.999 \\
Constant & 6.039 & 1.77 & 11.646 & 1 & 0.001 & 419.445 & & \\
\hline
\end{tabular}


A

ROC Curve

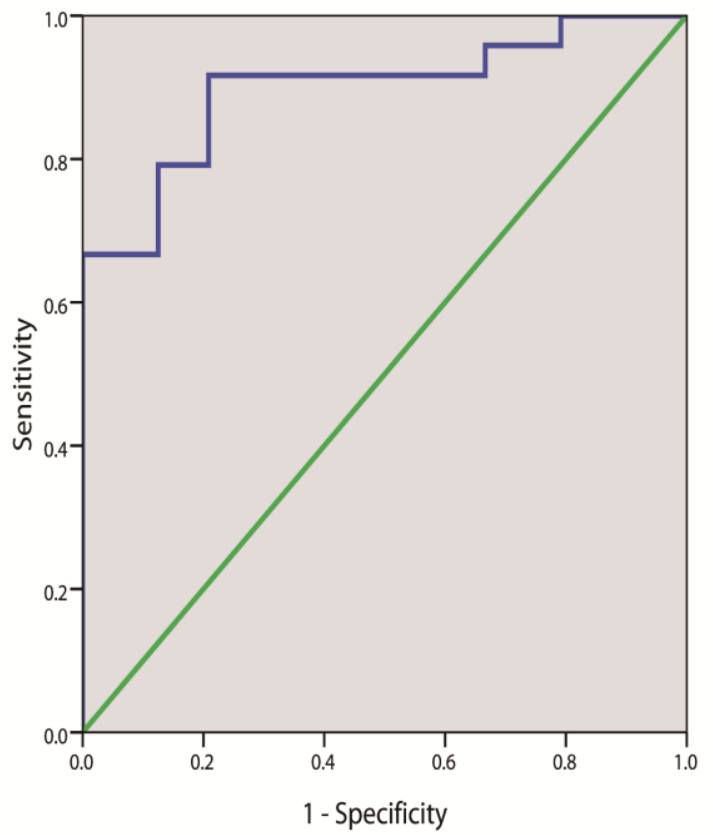

B

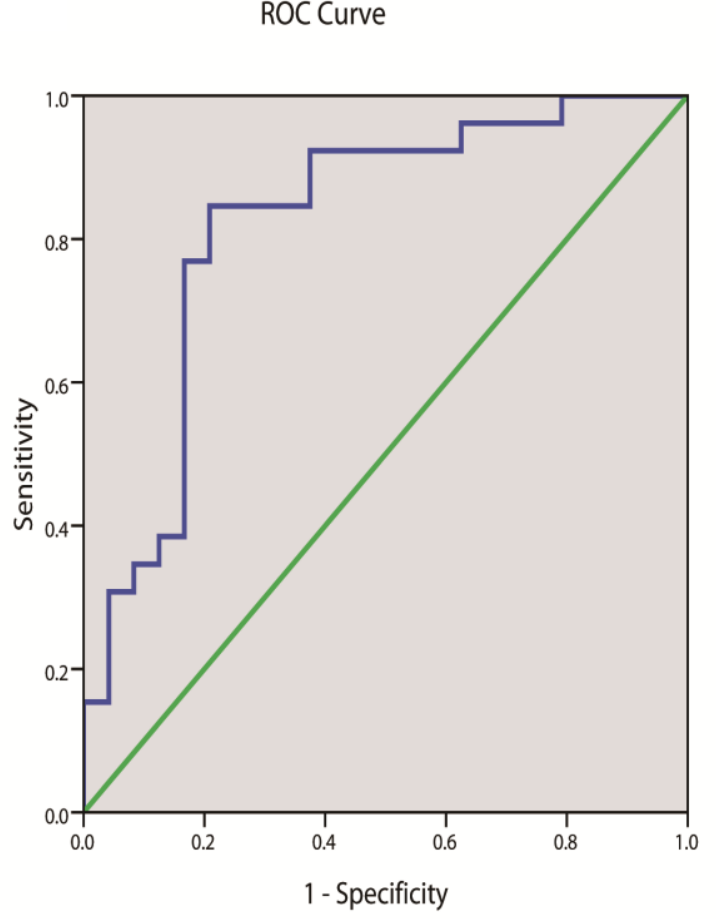

Figure1. ROC curve for (A) combination of peptides 1969.9 and $2213 \mathrm{Da}$, (B) combination of peptides 1781.8 and 1984.7 Da from multivariate logistic regression analysis

\subsection{Modeling for lung adenocarcinoma patients using mass spectra data}

For the purpose of discriminating lung adenocarcinoma patients from healthy controls, we constructed models using binary logistic regression analysis. The correlation of the 14 peptide peaks selected by ClinPro software was analyzed by spearman analysis. The peptides $\mathrm{m} / \mathrm{z}$ 1969.9, 2107.1,2 213.4, 1947.9 Da which are not only a significant AUC for discrimination $(\mathrm{p}<0.05$, table 4$)$ but also relatively independent to each other $(r<0.7, p<0.01)$ were substituted into the multivariate logistic regression, table 5. As shown in table 6, 1969.9 and 2213.4 Da enter the model for discriminating lung adenocarcinoma patients from healthy controls. The area under the curve of ROC curve (AUROC) is 0.898 (Figure 1A) and the accuracy is $85.45 \%$, with a sensitivity of $91.7 \%$ and a specificity of $79.2 \%$. These data demonstrate the capability of mass spectra data to discriminate lung adenocarcinoma patients from healthy controls. The classification equation for discriminating lung adenocarcinoma patients from healthy controls is as follows:

$\mathrm{p}=\left[1+\mathrm{e}^{(-0.006 \times \operatorname{mass} 1969.9-0.002 \times \operatorname{mass} 2213.4+6.039)}\right]^{-1}$

\subsection{Modeling for advanced lung adenocarcinoma with $\mathrm{BM}$ with mass spectra data}

For the purposes of discriminating advanced lung adenocarcinoma with BM from patients without BM, we compare the difference of the above 14 peaks(table 3 ) in advanced lung adenocarcinoma patients with BM as compared with patients without $\mathrm{BM}$, and only 5 peaks showed significant difference, table 7. As shown in table 8 , peptides $\mathrm{m} / \mathrm{z} 1781.8$ and $1984.7 \mathrm{Da}$ enters the model for discriminating advanced lung adenocarcinoma without BM from BM. The area under the curve of ROC curve (AUROC) is 0.822 (Figure 1B) and accuracy is $82.0 \%$, with a sensitivity of $84.6 \%$ and a specificity of $79.2 \%$. The classification equation for discriminating 
advanced lung adenocarcinoma patients with BM from patients without metastasis is as follows:

$\mathrm{p}=\left[1+\mathrm{e}^{(-0.003 \times \operatorname{mass} 1781.8+0.008 \times \operatorname{mass} 1984.7+0.16)}\right]^{-1}$

Table 7. Peptide peaks differentially expressed between lung adenocarcinoma patients without brain metastasis (NBM) and lung adenocarcinoma patients with brain metastasis(BM).

\begin{tabular}{lcccc}
\hline Peptides & NBM & BM & trend & p \\
\hline 1947.9 & 2033.4 & 2576.3 & $\uparrow$ & 0.004 \\
4096.2 & 189.5 & 417.3 & $\uparrow$ & 0.006 \\
1984.7 & 205.1 & 113.7 & $\uparrow$ & 0.008 \\
1781.8 & 314.2 & 562.8 & $\uparrow$ & 0.042 \\
2672 & 1246.3 & 687.1 & $\uparrow$ & 0.049 \\
\hline
\end{tabular}

\subsection{Prognostic Modeling for lung adenocarcinoma patients}

The optimal cut-off value for the 14 serum peptides was determined by ROC analysis, Table 9. The patients were divided into 2 groups by these cut-off values. Prognostic values of the 14 serum peptides which were highly specific for lung adenocarcinoma were evaluated by univariate analysis, as indicated in Table 10.

A

Survival Functions

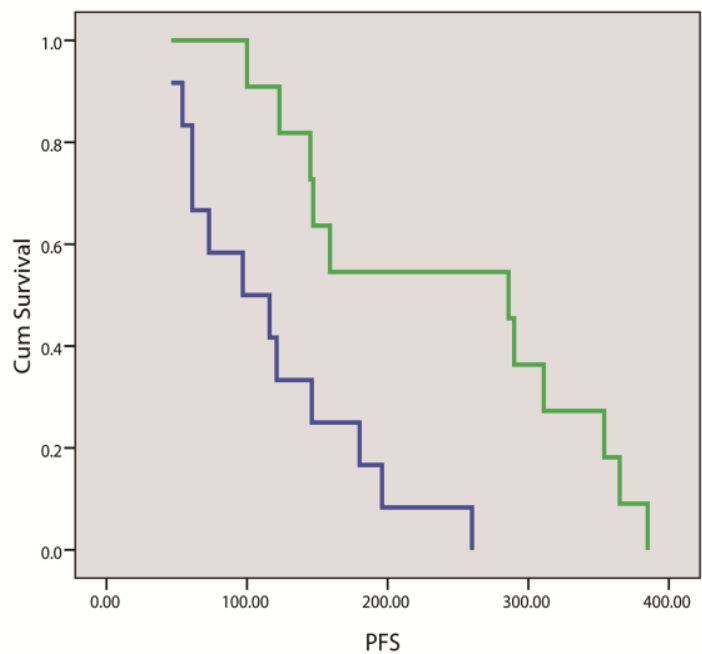

B

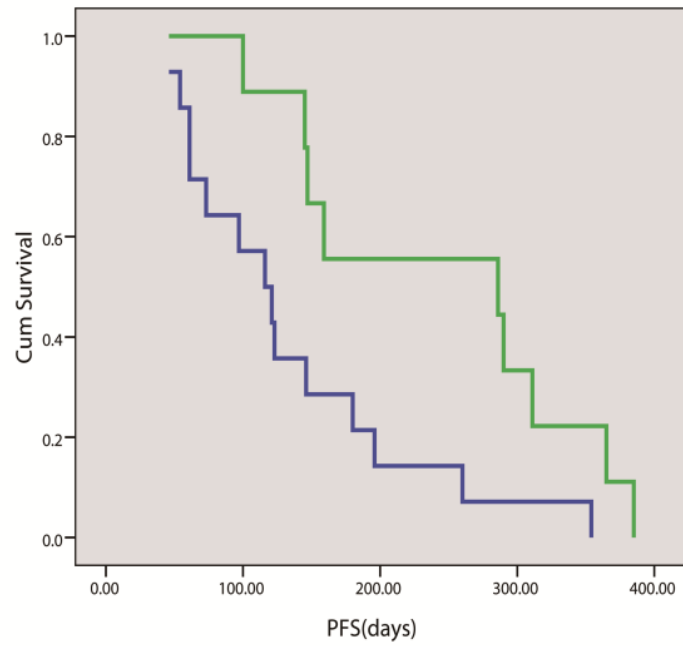

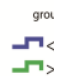

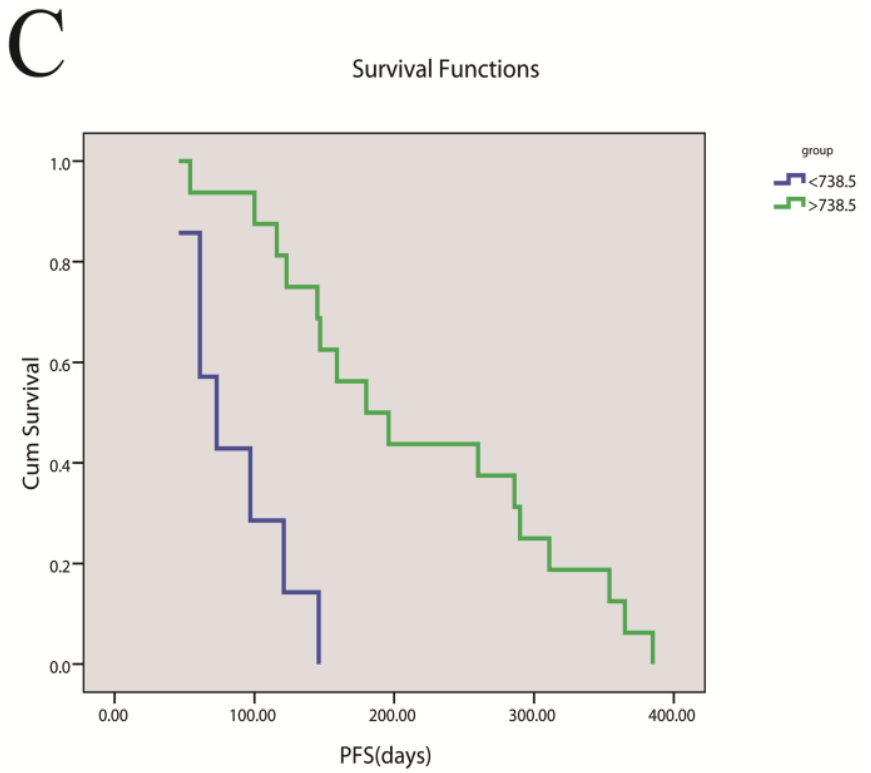

Figure 2. Kaplan-Meier survival curves of (A) peptiede $\mathrm{m} / \mathrm{z} 1969.9 \mathrm{Da}$, (B) peptiede $\mathrm{m} / \mathrm{z} 1984.7 \mathrm{Da}$, (C) peptiede $\mathrm{m} / \mathrm{z} 2095.2 \mathrm{Da}$

The Kaplan-Meier analysis indicated that $\mathrm{m} / \mathrm{z} \quad 1969.9, \quad 2095.2$ and $1984.7 \mathrm{Da}$ was significantly associated with the number of median PFS days, Table 10. A lower baseline 1969.9 (intensity $\leq 284$ ) was associated with an inferior outcomes in the univariate analysis when compared with patients with the intensity of $\mathrm{m} / \mathrm{z}$ 1969.9>284 (median PFS, 97 versus 286 days, $\mathrm{p}=0.002$, Table 10, Figure 2A). When stratified by peptide $\mathrm{m} / \mathrm{z} 1984.7 \mathrm{Da}$ (intensity >273 versus 
intensity $\leq 273$ ), the difference in median PFS survival curves was statistically significant (116 versus 286 days, $\mathrm{p}=0.0019$, Table 10, Figure $2 \mathrm{~B}$ ). Decreasing peptide $\mathrm{m} / \mathrm{z} 2095.2 \mathrm{Da}(\leq 154$ versus $>154)$ were also significantly associated with an unfavarable outcomes (median PFS, 116 versus 286 days, $p=0.0019$, Table 10, Figure 2C). All the above parameters with a $p$-value $<0.05$ were included in the multivariate Cox analysis. As summarized in Table 11, peptide m/z 1969.9 Da remained independent predictors of PFS $(\mathrm{p}=0.01)$ by multivariate analysis.

$\mathrm{p}=\left[1+\mathrm{e}^{(-0.006 \times \operatorname{mass} 1969.9)}\right]^{-1}$

Table 8. Peptides used in the multivariate logistic regression analysis for developing the classification model (NBM vs. BM)

\begin{tabular}{llccccccc}
\hline Peptides & B & S.E. & Wald & df & Sig. & $\operatorname{Exp}(\mathbf{B})$ & \multicolumn{2}{c}{$\mathbf{9 5 . 0 \%}$ C.I.for $\operatorname{EXP(B)}$} \\
\cline { 7 - 9 } & & & & & & & Lower & Upper \\
\hline 1781.8 & -0.003 & 0.001 & 4.304 & 1 & 0.038 & 0.997 & 0.994 & 1 \\
1984.7 & 0.008 & 0.005 & 2.79 & 1 & 0.095 & 1.008 & 0.999 & 1.017 \\
Constant & 0.16 & 0.77 & 0.043 & 1 & 0.835 & 1.174 & & \\
\hline
\end{tabular}

Table 9. List of the specificity, sensitivity and cutoff value for the 14 serum peptides which were evaluated to be specific for lung adenocarcinoma patien

\begin{tabular}{cccc}
\hline $\begin{array}{c}\text { Peptide } \\
\text { s }\end{array}$ & \multicolumn{1}{l}{ specificit } & \multicolumn{2}{l}{ sensitivit } \\
y & $\begin{array}{l}\text { Cutoff } \\
\text { values }\end{array}$ \\
\hline 1781.8 & 0.444 & 0.917 & 121.50 \\
1869.1 & 0.333 & 0.792 & 313.00 \\
1947.9 & 0.333 & 0.875 & 975.50 \\
1969.9 & 0.889 & 0.542 & 284.00 \\
1984.7 & 0.667 & 0.417 & 273.00 \\
2095.2 & 1.000 & 0.292 & 154.00 \\
2107.1 & 0.667 & 0.792 & 437.00 \\
2213.4 & 0.778 & 0.875 & 2750.50 \\
2663.8 & 0.889 & 0.542 & 619.50 \\
2865.8 & 0.667 & 1.000 & 226.00 \\
3244.4 & 0.778 & 0.750 & 738.50 \\
4096.2 & 0.792 & 0.875 & 225.50 \\
4214.1 & 0.333 & 0.875 & 975.50 \\
5910.2 & 0.778 & 0.583 & 977.00 \\
\hline
\end{tabular}

\subsection{Prognostic Modeling for advanced lung adenocarcinoma patients BM}

Pre-warning advanced

lung adenocarcinoma patients with $\mathrm{BM}$ is important to improve quality of life for patients, we then investigated the prognostic value of peptides $\mathrm{m} / \mathrm{z}$ 1969.9, 2095.2 and 1984.7 $\mathrm{Da}$ in predicting the prognosis of advanced lung adenocarcinoma patients with BM. As shown in table 12, peptide $\mathrm{m} / \mathrm{z}$ 1984.7 Da shows favourable value on pre warning lung adenocarcinoma patients with BM.

$\mathrm{p}=\left[1+\mathrm{e}^{(-0.002 \times \operatorname{mass} 1984.7)}\right]^{-1}$

\section{Discussion}

In present study, we have successfully detected a series of short peptides that differentially expressed in the serum of patients with lung adenocarcinoma as compared with healthy controls. We also constructed classification and prognostic models for lung adenocarcinoma patients with BM through MOLDI-TOF MS method. 
Table 10. Univariate analysis of predictive values of the selected 14 peptides for lung adenocarcinoma patients.

\begin{tabular}{|c|c|c|c|c|c|c|}
\hline \multirow[t]{2}{*}{ Peptides } & \multirow[t]{2}{*}{ Group } & \multirow[t]{2}{*}{$\begin{array}{c}\text { Progression } \\
\text { cases }\end{array}$} & \multicolumn{2}{|c|}{$\begin{array}{c}\text { Median PFS duration ( } \\
\text { days ) }\end{array}$} & \multirow[b]{2}{*}{$\chi^{2}$} & \multirow[b]{2}{*}{$\mathbf{P}$} \\
\hline & & & Estimate & Std Error & & \\
\hline \multicolumn{7}{|l|}{1781.8} \\
\hline & low & 7 & 180 & 97.163 & 0.066 & 0.797 \\
\hline & high & 43 & 145 & 25.715 & & \\
\hline \multicolumn{7}{|l|}{1869.1} \\
\hline & low & 11 & 147 & 26.291 & 0.013 & 0.91 \\
\hline & high & 39 & 145 & 26.517 & & \\
\hline \multicolumn{7}{|l|}{1947.9} \\
\hline & low & 9 & 54 & 7.5 & 0.989 & 0.32 \\
\hline & high & 41 & 147 & 10.157 & & \\
\hline \multicolumn{7}{|l|}{1969.9} \\
\hline & low & 26 & 97 & 37.239 & 9.451 & 0.002 \\
\hline & high & 24 & 286 & 78.719 & & \\
\hline \multicolumn{7}{|l|}{1984.7} \\
\hline & low & 30 & 116 & 22.45 & 5.536 & 0.019 \\
\hline & high & 20 & 286 & 189.32 & & \\
\hline \multicolumn{7}{|l|}{2095.2} \\
\hline & low & 15 & 73 & 15.712 & 14.394 & 0 \\
\hline & high & 35 & 180 & 37 & & \\
\hline \multicolumn{7}{|l|}{2107.1} \\
\hline & low & 39 & 123 & 26.517 & 0.448 & 0.503 \\
\hline & high & 11 & 260 & 125.976 & & \\
\hline \multicolumn{7}{|l|}{2213.4} \\
\hline & low & 46 & 145 & 19.072 & 0.425 & 0.514 \\
\hline & high & 4 & 147 & . & & \\
\hline \multicolumn{7}{|l|}{2663.8} \\
\hline & low & 24 & 116 & 14.313 & 0.695 & 0.404 \\
\hline & high & 26 & 147 & 11.258 & & \\
\hline \multicolumn{7}{|l|}{2865.8} \\
\hline & low & 0 & & & & \\
\hline & high & 23 & & & & \\
\hline \multicolumn{7}{|l|}{3244.4} \\
\hline & low & 14 & 116 & 15.922 & 0.484 & 0.487 \\
\hline & high & 36 & 147 & 9.604 & & \\
\hline \multicolumn{7}{|l|}{4096.2} \\
\hline & low & 6 & 61 & 12.247 & 0.142 & 0.707 \\
\hline & high & 44 & 146 & 2.236 & & \\
\hline \multicolumn{7}{|l|}{4214.1} \\
\hline & low & 24 & 121 & 14.313 & 1.393 & 0.238 \\
\hline & high & 26 & 147 & 11.258 & & 26 \\
\hline \multicolumn{7}{|l|}{5910.2} \\
\hline & low & 22 & 123 & 50.596 & 0.038 & 0.846 \\
\hline & high & 28 & 146 & 15.578 & & \\
\hline
\end{tabular}


Table 11.Peptides used in the multivariate Cox regression analysis for developing the prognostic model for lung adenocarcinoma patients.

\begin{tabular}{|c|c|c|c|c|c|c|c|c|c|}
\hline \multirow[t]{2}{*}{ Steps } & \multirow[t]{2}{*}{ Peptides } & \multirow[t]{2}{*}{ B } & \multirow[t]{2}{*}{ SE } & \multirow[t]{2}{*}{ Wald } & \multirow[t]{2}{*}{ df } & \multirow[t]{2}{*}{ Sig. } & \multirow[t]{2}{*}{$\operatorname{Exp}(B)$} & \multicolumn{2}{|c|}{ 95.0\% CI for $\operatorname{Exp}(B)$} \\
\hline & & & & & & & & Upper & Lower \\
\hline \multirow[t]{3}{*}{ Step 1} & 1969.922 & -0.01 & 0.006 & 2.616 & 1 & 0.106 & 0.99 & 1.002 & 0.979 \\
\hline & 2095.167 & 0.003 & 0.002 & 1.686 & 1 & 0.194 & 1.003 & 1.008 & 0.998 \\
\hline & 1984.683 & 0 & 0.003 & 0.015 & 1 & 0.902 & 1 & 1.006 & 0.993 \\
\hline \multirow[t]{2}{*}{ Step 2} & 1969.922 & -0.01 & 0.004 & 8.378 & 1 & 0.004 & 0.99 & 0.997 & 0.983 \\
\hline & 2095.167 & 0.003 & 0.002 & 3.101 & 1 & 0.078 & 1.003 & 1.007 & 1 \\
\hline Step 3 & 1969.922 & -0.006 & 0.002 & 6.623 & 1 & 0.01 & 0.994 & 0.999 & 0.989 \\
\hline
\end{tabular}

Table 12. Peptides used in the multivariate Cox regression analysis for developing the prognostic model for lung adenocarcinoma patients with BM.

\begin{tabular}{llrrrrrrrr}
\hline Steps & Peptids & B & \multicolumn{1}{l}{ SE } & Wald & df & Sig. & Exp(B) & \multicolumn{2}{c}{ 95.0\% CI for Exp(B) } \\
\hline Step 1 & 1969.922 & 0.01 & 0.01 & 1.026 & 1 & 0.0311 & 1.01 & 1.029 & 0.991 \\
& 2095.167 & -0.003 & 0.003 & 0.983 & 1 & 0.0321 & 0.997 & 1.003 & 0.992 \\
& 1984.683 & -0.008 & 0.007 & 1.346 & 1 & 0.0246 & 0.992 & 1.006 & 0.978 \\
Step 2 & 1969.922 & 0.001 & 0.004 & 0.097 & 1 & 0.0756 & 1.001 & 1.01 & 0.993 \\
& 1984.683 & -0.003 & 0.005 & 0.439 & 1 & 0.0507 & 0.997 & 1.006 & 0.988 \\
Step 3 & 1984.683 & -0.002 & 0.002 & 0.655 & 1 & 0.0418 & 0.998 & 1.003 & 0.994 \\
\hline
\end{tabular}

Current knowledge of cellular regulation indicates that many networks operate at the translational levels. Proteomic technologies will help further understand the interaction that connect the serum or plasma with tumor microenvironment. Peptidomic maps associated with lung adenocarcinoma were drawn in this study. In particular, the prominent peptides that have a greater than twofold change in intensity, such as $\mathrm{m} / \mathrm{z}$ 1781.8,1869.1, 1969.9,1984.7, 2095.2, 2213.4, 2663.8, 3244.4, 4096. 2 and 4214.1 including 7 upregulated peptide $(\mathrm{m} / \mathrm{z}$ 1781.8,1869.1, 1969.9, 2663.8, 3244.4, 4096. 2 and 4214.1, ) and 3 downregulated peptides $(\mathrm{m} / \mathrm{z}$ 1984.7, 2095.2 and 2213.4) were detected predominantly in serum from lung adenocarcinoma patients as compared to serum from healthy volunteers.
Of these, a cluster of two peaks at $\mathrm{m} / \mathrm{z}$ 1969.9 and 2213.4 Da achieved a classification capacity with the accuracy of close to $85.45 \%$ (a specificity of $79.2 \%$, and a sensitivity of $91.7 \%$ ) to discriminate lung adenocarcinoma from healthy volunteers. The peak 1969.9 Da, which is a fragment of transthyretin precursor, was more highly expressed in lung adenocarcinoma patients than in healthy controls in our study. Previous data illustrated that peaks of transthyretin precursor (TTR) fragments have frequently been detected in papillary thyroid cancer, pancreatic carcinoma and meningioma after a MALLDITOF method $(10,15,17)$. One of the peaks associated with TTR was reported to be overexpressed in papillary thyroid cancer and has been identified as fragment of TTR by 2-DE, MALDI-TOF/MS and Western blot (10). A fragment of TTR was reported as being 
overexpressed in serum of pancreatic carcinoma patients receiving low dose of warfarin but not in those on high dose of warfarin using iTRAQcoupled LC-MS/MS(17). Other studies have identified an specific cleavage fragment of TTR in human cerebrospinal fluid of patients with meningioma using two-dimensional electrophoresis and electrospray quadrupole timeof-flight tandem mass spectrometry analysis(15).All these suggested the potential of 1969.9 $\mathrm{Da}$ as a biomarker for cancer and the possible relationship between TTR and lung adenocarcinoma, which would be explored in our further work. In addition, peak m/z 2213.4 Da, another peptide in our model for lung adenocarcinoma patients, is one fragment of fibrinogen alpha chain precursor. Fragments of fibrinogen alpha chain precursor at $\mathrm{m} / \mathrm{z} 1264.6 \mathrm{Da}$ and 3245.6Da have been identified as diagnostic biomarker for nasopharyngeal carcinoma (25), IgA nephropathy(11) and acute graft versus host disease (aGVHD)(27).

Model including peptides at $\mathrm{m} / \mathrm{z} 1781.8$ and 1984.683 Da achieved a accuracy of $82 \%$ with a sensitivity of $84.6 \%$ and a specificity of $79.2 \%$ to discriminate advanced lung adenocarcinoma with BM from patients without BM. Peptide $\mathrm{m} / \mathrm{z}$ 1781.8 was identified as a degraded fragment of ADP-ribosylarginine hydrolase (ARH1), which can regulates cell proliferation and tumorigenesis(13). Meanwhile, Peptide 1984.7, a degraded derivative of thymosin beta-4-like protein 3(TMSL3), may be an significant prognostic biomarker for lung adenocarcinoma patients with BM. Gianazza et al also found an up-expressed fragment of TMSL3 at 5337.62 Da by MALDI-TOF MS serum in renal cell carcinoma(9). And the potential prognostic value of peptide 1984.7 remains to be further investigated

The m/z 1969.9 Da may also serve as an significant prognostic biomarker for lung adenocarcinoma patients while $\mathrm{m} / \mathrm{z}$ 1984.7 Da serve as an significant prognostic biomarker for advanced lung adenocarcinoma with BM. Few paper have investigated the prognostic value of peptide 1969.9 and 1984.7 Da. Peptides $\mathrm{m} / \mathrm{z}$ 1969.9 and 1984.7 Da may be defined as the leading differential peptides associated with prognosis, worthy of further sequence determination and function analysis.

Collectively, the classification and prognostic model we have set up will have application in providing information for diagnosis and prognosis of lung adenocarcinoma patients, and may provide a better understanding of brain metastasis in lung adenocarcinoma, finally resulting in an improvement in outcomes of patients. However, the sample size is limited and we will confirm the usefulness of our currently identified peptides in larger patient cohorts in further work. After this confirmation, we will then determine the function of the peptides of interest.

\section{Acknowledgements}

The authors thank the staff in the Department of Clinical Biochemistry and the Department of Radiology at the Chinese PLA General Hospital for their support. This study was supported by the National Key Technology Support Program of China (grant number 2009BAI86B05) and by the National High-tech Technology Research and Development Program of China (2011AA 02A 111).

\section{References}

1. Chemotherapy in non-small cell lung cancer: a meta-analysis using updated data on individual patients from 52 randomised clinical trials. Non-small Cell Lung Cancer Collaborative Group. Bmj 311(7010):899909, 1995.

DOI:org/10.1136/bmj.311.7010.899.

2. Aldred S., Grant M.M. and Griffiths H.R. The use of proteomics for the assessment of clinical samples in research. Clinical biochemistry 37(11):943-952, 2004. DOI: 10.1016/j.clinbiochem.2004.09.002.

3. Banks R.E., Dunn M.J., Hochstrasser D.F., Sanchez J.C., Blackstock W., Pappin D.J. and Selby P.J. Proteomics: new perspectives, new biomedical opportunities. Lancet 
356(9243):1749-1756,

2000

DOI:10.1016/S0140-6736(00)03214-1.

4. de Noo M.E., Mertens B.J., Ozalp A., Bladergroen M.R., van der Werff M.P., van de Velde C.J., Deelder A.M. and Tollenaar R.A. Detection of colorectal cancer using MALDI-TOF serum protein profiling. European journal of cancer 42(8):1068-1076, 2006.DOI: http://dx.doi.org/10.1016/j.ejca.2005.12.023

5. Etzioni R., Urban N., Ramsey S., McIntosh M., Schwartz S., Reid B., Radich J., Anderson G. and Hartwell L. The case for early detection. Nature reviews. Cancer 3(4):243-252, 2003. DOI:10.1038/nrc1041.

6. Fortin D., Gendron C., Boudrias M. and Garant M.P. Enhanced chemotherapy delivery by intraarterial infusion and bloodbrain barrier disruption in the treatment of cerebral metastasis. Cancer 109(4):751-760, 2007. DOI: $10.1002 / \mathrm{cncr} .22450$.

7. Freed G.L., Cazares L.H., Fichandler C.E., Fuller T.W., Sawyer C.A., Stack B.C., Jr., Schraff S., Semmes O.J., Wadsworth J.T. and Drake R.R. Differential capture of serum proteins for expression profiling and biomarker discovery in pre- and posttreatment head and neck cancer samples. The Laryngoscope 118(1):61-68, 2008. DOI: 10.1097/MLG.0b013e31814cf389.

8. Gavrilovic I.T. and Posner J.B. Brain metastases: epidemiology and pathophysiology. Journal of neuro-oncology 75(1):5-14, 2005. DOI:10.1007/s11060-0048093-6.

9. Gianazza E., Chinello C., Mainini V., Cazzaniga M., Squeo V., Albo G., Signorini S., Di Pierro S.S., Ferrero S., Nicolardi S., van der Burgt Y.E., Deelder A.M. and Magni F. Alterations of the serum peptidome in renal cell carcinoma discriminating benign and malignant kidney tumors. Journal of proteomics 76 Spec No.:125-140, 2012. DOI: 10.1016/j.jprot.2012.07.032.

10. Giusti L., Iacconi P., Ciregia F., Giannaccini G., Donatini G.L., Basolo F., Miccoli P., Pinchera A. and Lucacchini A. Fine-needle aspiration of thyroid nodules: proteomic analysis to identify cancer biomarkers.
Journal of proteome research 7(9):40794088, 2008. DOI: 10.1021/pr8000404.

11. Kaneshiro N., Xiang Y., Nagai K., Kurokawa M.S., Okamoto K., Arito M., Masuko K., Yudoh K., Yasuda T., Suematsu N., Kimura $\mathrm{K}$. and Kato T. Comprehensive analysis of short peptides in sera from patients with $\operatorname{IgA}$ nephropathy. Rapid communications in mass spectrometry : RCM 23(23):3720-3728, 2009. DOI: $10.1002 / \mathrm{rcm} .4315$.

12. Kantarjian H., Farha P.A., Spitzer G., Murphy W.K. and Valdivieso M. Systemic combination chemotherapy as primary treatment of brain metastasis from lung cancer. Southern medical journal 77(4):426430, 1984. DOI:10.1097/00007611198404000-00005

13. Kato J., Zhu J., Liu C., Stylianou M., Hoffmann V., Lizak M.J., Glasgow C.G. and Moss J. ADP-ribosylarginine hydrolase regulates cell proliferation and tumorigenesis. Cancer research 71(15):5327-5335, 2011. DOI: 10.1158/0008-5472.CAN-10-0733

14. Ketterlinus R., Hsieh S.Y., Teng S.H., Lee H. and Pusch W. Fishing for biomarkers: analyzing mass spectrometry data with the new ClinProTools software. BioTechniques Suppl:37-40, 2005. DOI: $10.2144 / 05386$ SU07

15. Kim J.H., Lee S.K., Yoo Y.C., Park N.H., Park D.B., Yoo J.S., An H.J., Park Y.M. and Cho K.G. Proteome analysis of human cerebrospinal fluid as a diagnostic biomarker in patients with meningioma. Medical science monitor : international medical journal of experimental and clinical research 18(11):BR450-460,

2012. DOI: $10.12659 / M S M .883538$

16. Kristensen C.A., Kristjansen P.E. and Hansen H.H. Systemic chemotherapy of brain metastases from small-cell lung cancer: a review. Journal of clinical oncology : official journal of the American Society of Clinical Oncology 10(9):1498-1502, 1992.

17. Lv S., Gao J., Zhu F., Li Z., Gong Y., Xu G. and Ma L. Transthyretin, identified by proteomics, is overabundant in pancreatic juice from pancreatic carcinoma and originates from pancreatic islets. Diagnostic 
cytopathology 39(12):875-881, 2011. DOI: $10.1002 / \mathrm{dc} .21484$.

18. Motari E., Zheng X., Su X., Liu Y., Kvaratskhelia M., Freitas M. and Wang P.G. Analysis of Recombinant CD24 Glycans by MALDI-TOF-MS Reveals Prevalence of Sialyl-T Antigen. American journal of biomedical sciences 1(1):1-11, 2009.

19. Newman S.J. and Hansen H.H. Proceedings: Frequency, diagnosis, and treatment of brain metastases in 247 consecutive patients with bronchogenic carcinoma. Cancer 33(2):492496, $\quad 1974 . \quad$ DOI: $10.1002 / 1097-$ 0142(197402)33:2<492::AIDCNCR2820330225>3.0.CO;2-O.

20. Qiu F., Liu H.Y., Dong Z.N., Feng Y.J., Zhang X.J. and Tian Y.P. Searching for Potential Ovarian Cancer Biomarkers with Matrix-Assisted Laser Desorption/Ionization Time-of-Flight Mass Spectrometry. American journal of biomedical sciences 1(1):80-90, 2009.

21. Shao C., Tian Y., Dong Z., Gao J., Gao Y., Jia X., Guo G., Wen X., Jiang C. and Zhang $\mathrm{X}$. The Use of Principal Component Analysis in MALDI-TOF MS: a Powerful Tool for Establishing a Mini-optimized Proteomic Profile. American journal of biomedical sciences 4(1):85-101, 2012.

22. Shimizu I. and Prasad C. Relationship between $[3 \mathrm{H}]$ mazindol binding to dopamine uptake sites and $[3 \mathrm{H}]$ dopamine uptake in rat striatum during aging. Journal of neurochemistry 56(2):575-579, 1991. DOI: 10.1111/j.1471-4159.1991.tb08188.x.

23. Sigari N., Mohsenpour B., Nikkhoo B., Ghaderi B., Afkhamzadeh A., Azadi N.A.,
Fathi F. and Abdi M. Determination of the best prognostic value of serum tumor markers in patients with suspected lung cancer in an Iranian population. Clinical laboratory 60(1):23-27, 2014.

24. Sorensen J.B., Hansen H.H., Hansen M. and Dombernowsky P. Brain metastases in adenocarcinoma of the lung: frequency, risk groups, and prognosis. Journal of clinical oncology : official journal of the American Society of Clinical Oncology 6(9):1474-1480, 1988.

25. Tao Y.L., Li Y., Gao J., Liu Z.G., Tu Z.W., Li G., Xu B.Q., Niu D.L., Jiang C.B., Yi W., Li Z.Q., Li J., Wang Y.M., Cheng Z.B., Liu Q.D., Bai L., Zhang C., Zhang J.Y., Zeng M.S. and Xia Y.F. Identifying FGA peptides as nasopharyngeal carcinoma-associated biomarkers by magnetic beads. Journal of cellular biochemistry 113(7):2268-2278, 2012. DOI: $10.1002 /$ jcb. 24097.

26. Wattiez R. and Falmagne P. Proteomics of bronchoalveolar lavage fluid. Journal of chromatography. B, Analytical technologies in the biomedical and life sciences 815(12):169-178, 2005 . $\quad$ DOI: 10.1016/j.jchromb.2004.10.029.

27. Zhang C.Y., Wang S.H., Huang W.R., Guo G.H., Zhang Z.H., Mou W.J., Yu L. and Tian Y.P. A novel differential predict model based on matrix-assisted laser ionization time-offlight mass spectrometry and serum ferritin for acute graft-versus-host disease. BioMed research international 2013:563751, 2013. 